\title{
O sistema de arbitragem internacional no século XIX: uma análise histórico-jurídica*
}

\author{
The international arbitration system in the 19th century: a historical-legal analysis
}

\author{
Pedro Caridade de Freitas ${ }^{* *}$
}

\section{REFERÊNCIA}

FREITAS, Pedro Caridade de. O sistema de arbitragem internacional no século XIX: uma análise históricojurídica. Revista da Faculdade de Direito da UFRGS, Porto Alegre, n. 43, p. 73-96, ago. 2020. DOI: $<$ https://doi.org/10.22456/0104-6594.105721>.

\section{RESUMO}

A criação de um sistema de jurisdição internacional, com um tribunal internacional que aplique o Direito Internacional, é um dos objectivos dos Estados desde a Paz de Vestefália. O recurso à arbitragem internacional surge como um modelo de jurisdição internacional utilizado pelos Estados ao longo do século XIX. No início a arbitragem foi essencialmente voluntária, mas no final do século XIX tentou, sem sucesso, na Convenção de Haia de 1899, um sistema de arbitragem necessária.

\section{PALAVRAS-CHAVE}

Arbitragem Internacional. Tribunal Internacional. Paz Perpétua.

\section{ABSTRACT}

The creation of a system of international jurisdiction, with an international court that applies International Law, is one of the objectives of the States since the Peace of Westephalia. The use of international arbitration emerges as a model of international jurisdiction used by states throughout the 19th century. In the beginning, arbitration was essentially voluntary, but by the end of the 19th century it was sought, although without success, to implement a necessary arbitration system in the Hague convention of $1899 .$.

\section{KEYWORDS}

International Arbitration, International Court, Perpetual Peace.

\section{SUMÁRIO}

1. Razão de ordem. 2. Evolução da jurisdição internacional. 3. A arbitragem internacional no século XIX. 4. A criação de um Tribunal de Arbitragem Internacional. Referências. Dados da publicação.

\footnotetext{
* O presente estudo corresponde a uma conferência proferida, no dia 8 de Setembro de 2016, nas V Jornadas Hispano-Lusas de Historia del Derecho, realizadas na Faculdade de Direito de Santiago de Compostela, dedicadas ao tema Experiencia Histórica del Control Judicial em España y Portugal (siglos XVI-XX). Algumas das ideias explanadas no presente artigo encontram-se em FREITAS, Pedro Caridade de. Portugal e a Comunidade Internacional na Segunda Metade do Século XIX. Lisboa: Quid Juris, 2012. pp. 525-576.

** Professor Associado da Faculdade de Direito da Universidade de Lisboa. Investigador do Instituto de Investigação Interdisciplinar da Faculdade de Direito da Universidade de Lisboa (IURIS).
} 


\section{RAZÃO DE ORDEM}

O presente estudo tem como objetivo analisar as soluções encontradas pelos Estados e defendidas pelos juristas e filósofos desde o século XVII até ao século XIX, com o intuito de estabelecer um sistema que permitisse a gênese de uma jurisdição internacional.

Durante o século XIX e, na dificuldade de se criar um tribunal internacional, pela falta de consenso entre os Estados, os Estados optam pela arbitragem internacional como instrumento de resolução pacífica dos conflitos.

A arbitragem internacional aperfeiçoa-se ao longo do século XIX, permitindo o surgimento, em 1899, do Tribunal Permanente de Arbitragem Internacional, que ainda hoje existe, com sede na cidade da Haia, e que antecede os diversos modelos jurisdicionais do século XX.

Ao longo do século XX surgem vários tribunais internacionais que sedimentam o sistema de jurisdição internacional. Com a Sociedade das Nações é constituído um Tribunal Permanente de Justiça Internacional e com a Organização das Nações Unidos surge, em 1945, o atual Tribunal Internacional de Justiça, com jurisdição apenas sobre os Estados.

Além destes Tribunais e com jurisdição sobre Estados e pessoas são criados diversos tribunais de direitos humanos, como o Tribunal Europeu dos Direitos Humanos e a Corte Interamericana de Direitos Humanos.

Ao longo do século XX surgem ainda tribunais ad-hoc para resolver situações específicas, como os tribunais de Nurembergue e Tóquio, em 1946, que julgam os crimes da II Guerra Mundial, o Tribunal Penal Internacional para a antiga Iugoslávia ou o Tribunal Penal Internacional para a Ruanda. A tutela penal internacional consolida-se com a criação, em 17 de Julho de 1998, pelo Tratado de Roma, do Tribunal Penal Internacional. 


\section{EVOLUÇÃO DA JURISDIÇÃO INTERNACIONAL}

1. A busca incessante da paz e a criação de meios para que esta se concretize são objetivos a atingir pelos filósofos e pelos juristas. Várias foram as tentativas teóricas de construção de um sistema que promova a paz em detrimento da guerra. ${ }^{1}$

As soluções encontradas são diversas e variam entre a solução jurídico-forense de Vitória e a política de Kant.

Francisco de Vitória defende como forma de controlar a guerra, a existência de um Tribunal Permanente das Nações. Este Tribunal tem como objetivo substituir o exercício da força de um Estado contra outro por uma ação judicial. A criação do Tribunal é facilitada pela visão de Vitória, que, em matéria de justiça, entende não haver indivíduos, nem nações, mas apenas litigantes perante um Tribunal, fosse ele nacional ou internacional. ${ }^{2}$

Em Vitória a guerra constitui uma demanda sedimentada no direito da força, dada a ausência de um Tribunal Superior a quem pudesse ser submetida a disputa, pelo que o teólogo espanhol olha para os Estados e para os indivíduos da mesma forma, propugnando a resolução dos conflitos por uma via pacífica, a judicial. ${ }^{3}$

2. Os séculos XVIII e XIX conhecem a defesa da construção de projetos de organização internacional de tipo federal. ${ }^{4}$ Autores como Kant, Rousseau, Bentham, Lorimer e Bluntschli são defensores de um modelo federal que permita uma união de povos.

O Abée de Saint Pierre ${ }^{5}$ (1658-1743) defende a criação de uma associação de Estados europeus que renuncie à guerra e institua um sistema de arbitragem obrigatória e uma força

\footnotetext{
1 Lobo d'Avila Lima, num trabalho sobre a Sociedade das Nações, realça o trabalho de Silvestre Pinheiro Ferreira como precursor da ideia de sociedade das nações, ao propor uma tesouraria comum dos Estados confederados, mediante um acordo entre os vários bancos nacionais, procede a uma análise da ideia de sociedade das nações como instrumento para promover a paz entre as Nações. Cfr. Lobo d'Ávila Lima, Da Sociedade das Nações, Lisboa, J. Rodrigues e C. ${ }^{\text {a }}$, 1927, pp. 5-16. Vide também MALTEZ, José Adelino. Princípios de Ciência Política. Introdução à Teoria Política. 2. ed. Com prefácio de Adriano Moreira. Lisboa: Instituto Superior de Ciências Sociais e Políticas, 1996. pp. 475-485.

2 SCOTT, James Brown. El Origen Español del Derecho Internacional Moderno. Prólogo de Camilo Barcia Trelles. Valladolid: Universidad de Valladolid, 1928.pp. 102-103.

3 Idem, p. 108.

4 Para os projectos federativos medievais vide MALTEZ, op. cit., pp. 243-244.

5 Escreveu entre outras obras um Projet pour rendre la paix perpétuelle en Europe, Utreque, 1713 e com edição definitiva em 1717.
} 
internacional, com o fim de manter a paz e a aliança entre os vários Estados $^{6}$, garantindo-se, deste modo, as formas de governo existentes após a Paz de Utreque.

A federação idealizada pelo Abée de Saint Pierre é constituída por uma assembleia de Soberanos federados denominada Senado, a quem compete decidir os destinos da federação e, caso necessário, declarar guerra, quer contra Estados federados ${ }^{7}$, que não cumpram as decisões da maioria, quer contra Estados não federados.

A representação no Senado não é feita com base no princípio da igualdade dos Estados, propugnado desde a Paz de Vestefália ${ }^{8}$. Se os Estados grandes tinham direito de voto, os mais pequenos tinham-no em grupo, sendo atribuído um voto por cada grupo. ${ }^{9}$

3. Um projeto semelhante ao do Abée de Saint Pierre foi construído por Immanuel Kant, no opúsculo A Paz Perpétua. ${ }^{10}$

Para Kant, que valoriza o indivíduo nas relações internacionais, em detrimento dos Estados, a paz constitui o fim de todas as hostilidades, pelo que um simples armistício, enquanto adiamento da paz, não basta para que os Estados deixem de estar em guerra, uma vez que só põe fim a uma situação concreta de guerra e pode adiar outras guerras futuras. ${ }^{11}$

O sistema de pensamento kantiano em torno da paz perpétua centra-se em três ideias: os Estados não devem destruir a confiança que os povos se devem mutuamente, devem respeitar-se e não devem criar condições que os levem à guerra.

Uma vez que o estado de natureza para Kant é um estado de guerra, "isto é, um estado em que, embora não exista sempre uma explosão das hostilidades, há sempre, no entanto, uma ameaça constante" ${ }^{12}$, torna-se necessário instaurar um estado de paz que, prescrevendo a igualdade ${ }^{13}$ entre os Estados, permita o fim da guerra.

6 TRUYOL Y SERRA, António. Noções Fundamentais de Direito Internacional Público. 2. ed. Refundida e aumentada. Tradução de R. Ehrhardt Soares. Coimbra: Arménio Amado, 1962. pp. 10-11 e Cfr. MALTEZ, José Adelino. Princípios de Ciência Política. Introdução à Teoria Política. 2. ed. Com prefácio de Adriano Moreira. Lisboa: Instituto Superior de Ciências Sociais e Políticas, 1996. pp. 487-490.

7 NUSSBAUM, Arthur. História del Derecho Internacional. v. 1 e 2. Madrid: Editorial Revista de Derecho Privado, [s. d.]. p. 154.

8 FREITAS, Pedro Caridade de. História do Direito Internacional Público. Da Antiguidade à II Guerra Mundial. Cascais: Princípia, 2015. pp. 86 e seguintes.

9 Cfr. NUSSBAUM, op. cit., p. 154.

10 Cfr. KANT, Immanuel. A Paz Perpétua e Outros Opúsculos. Lisboa: Edições 70, 2008, pp. 129-185. Vide MALTEZ, op. cit., pp. 490-493. PEREIRA, Maria de Assunção do Vale. A Intervenção Humanitária no Direito Internacional Contemporâneo. Coimbra: Coimbra Ed., 2009. pp. 151-165.

11 Cfr. KANT, op. cit., p. 130.

12 Cfr. idem, pp. 136-137.

13 Idem, p. 134. 
A paz perpétua só pode ser concretizada através da criação de uma federação de Estados livres que, "não se [propunha] obter o poder do Estado, mas simplesmente manter e garantir a paz de um Estado para si mesmo e, ao mesmo tempo, a dos outros Estados federados, sem que estes devam por isso (como os homens no estado de natureza) submeter-se a leis públicas e à sua coação ${ }^{14}$." Por isso, é que Kant defende a existência de uma federação de Estados e não uma federação de povos, uma vez que esta última implica a relação entre um superior e um inferior.

A federação é constituída por Estados iguais, ligados por um contrato, sem supremacia de uns em relação aos outros, e que tentam, em conjunto, manter a paz. A paz é mais facilmente alcançada, na ideia de Kant, se os Estados que compõem a federação tiverem uma constituição interna republicana ${ }^{15}$, baseada em três princípios: a liberdade e igualdade dos membros da sociedade e a dependência de todos em relação a uma legislação comum. ${ }^{16} \mathrm{~A}$ liberdade dos Estados que se congrega na confederação constitui um requisito prévio à concretização da paz perpétua. ${ }^{17}$

A federação de Estados é regida por um direito cosmopolita, entendido como direito público da humanidade e complemento da paz perpétua. ${ }^{18}$

Em Kant ${ }^{19}$, por exemplo, o direito regula as relações externas entre as pessoas, na medida em que as suas ações podem influir umas nas outras. A vontade de uma pessoa deve concordar com a vontade de outra, segundo a lei da liberdade. Esta lei, considerada por Kant como inata, implica uma imposição exterior para impedir uma possível violação. Como contraposição ao direito inato, Kant identifica um direito adquirido que constitui um direito privado e um direito público, em que este último regula a vida social dos indivíduos numa comunidade juridicamente ordenada. ${ }^{20}$

14 KANT, Immanuel. A Paz Perpétua e Outros Opúsculos. Lisboa: Edições 70, 2008. pp. 145-146. 15 A constituição republicana tinha para Kant vantagens quando chegasse o momento de enveredar por uma solução de guerra ou paz. Kant foi neste aspecto muito claro: [Se (...) se exige o consentimento dos cidadãos para decidir "se deve ou não haver guerra", então, nada é mais natural do que deliberar muito em começarem um jogo tão maligno, pois têm de decidir para si próprios todos os sofrimentos da guerra (como combater, custear as despesas da guerra com o seu próprio património, reconstruir penosamente a devastação que ela deixa atrás de si e, por fim e para cúmulo dos males, tomar sobre si o peso das dívidas que nunca acaba (em virtude de novas e próximas guerras) e tornar amarga a paz. Pelo contrário, numa constituição em que o súbdito não é cidadão, que, por conseguinte, não é uma constituição republicana, a guerra é a coisa mais simples do mundo, porque o chefe do Estado não é um membro do Estado, mas o seu proprietário, e a guerra não lhe faz perder o mínimo dos seus banquetes, caçadas, palácios de recreio, festas cortesãs, etc.], Idem, pp. 139-140.

16 Idem, pp. 137-138.

17 NUSSBAUM, Arthur. História del Derecho Internacional. v. 1 e 2. Madrid: Editorial Revista de Derecho Privado, [s. d.]. op. cit., p. 156.

18 Cfr. KANT, op. cit., p. 151.

19 Sobre o pensamento jus-filosófico de Kant vide MONCADA, Cabral de. Filosofia do Direito e do Estado. v. 1. Coimbra: Coimbra Ed., [s/d]. pp. 249-270.

20 Cfr. ABBAGNANO, Nicola. Historia da Filosofia. v. 8. Lisboa: Presença, 1984. p. 112. 
Esta comunidade é o Estado, constituído por três poderes: legislativo, executivo e judicial. O poder legislativo é atribuído à vontade colectiva do povo que por consenso se agrupa em sociedade civil e em Estado. Os homens não se encontram unidos por interesses, mas pela Razão, entendida como universal legisladora. ${ }^{21}$

No âmbito externo, Kant desenvolve o conceito de direito cosmopolita, que se funda na ideia de uma perpétua associação pacífica de todos os povos da terra. A paz perpétua é um dos objetivos a atingir, por constituir um dever moral e político de todos os Estados. A paz é alcançada através da realização de uma sociedade política universal que compreende sob a mesma legislação os diversos Estados e garante o desenvolvimento do Homem. ${ }^{22}$

4. Bentham no Plano para a paz perpétua (1786-1789), Kant no Ensaio philosophico acerca da paz perpétua (1795) e Schelling, que defende uma federação de todos os Estados, são defensores do instituto da arbitragem, bem como da constituição de um tribunal comum à comunidade de Estados. Leibnitz, Volney, Condorcet, os economistas Turgot e Smith, os poetas Lessing e Herder são também arautos da arbitragem.

A construção de uma sociedade de Estados, que pode assumir a forma de confederação, e que se inspira na figura do Estado, não é mais do que uma necessidade de fundar e legitimar o Direito Internacional. ${ }^{23}$ Como cada Estado, também o Estado Universal tem um poder legislativo, um executivo e um judicial.

Para melhor implementar a arbitragem, autores houve, como Schelling, que propõem a criação de uma federação de Estados que imponha as suas decisões, mesmo com perda da independência dos Estados. Não pondo em causa a independência de cada Estado, Saint-Simon elabora, em 1814, a obra De la réorganisation de la Société européenne, ou e de la nécessité et des moyens de rassembler les peuples de l'Europe en un seul corps politique en conservant à chacun son indépendance nationale. Inspirando-se no modelo medieval, SaintSimon propõe a criação de uma sociedade europeia baseada na ciência, considerada como o "novo cristianismo". ${ }^{24}$

21 MONCADA, Cabral de. Filosofia do Direito e do Estado. V. 1. Coimbra: Coimbra Ed., [s/d]. p. 264.

22 ABBAGNANO, Nicola. Historia da Filosofia. v. 8. Lisboa: Presença, 1984. p. 114.

23 Cfr. FIORE, Pasquale. Le Droit International Codifié et sa Sanction Juridique. Tradução do italiano por Ch. Antoine. Paris: A. Pedone, 1911. p. 21.

24 MALTEZ, José Adelino. Princípios de Ciência Política. Introdução à Teoria Política. 2. ed. Com prefácio de Adriano Moreira. Lisboa: Instituto Superior de Ciências Sociais e Políticas, 1996. pp. 508-509. 
O projeto de Saint-Simon não se dirige aos Príncipes, mas aos Povos e propõe a eleição de um Parlamento europeu, com um Rei e duas Câmaras, a de Pares, de nomeação régia, e a outra com representantes das categorias econômicas e profissionais.

Os economistas oitocentistas tiveram uma orientação diversa. Segundo eles, o árbitro supremo só pode existir se os povos formassem entre si uma associação, após terem adotado as instituições republicanas. Nesta federação de Estados da Europa, o poder legislativo, judiciário e executivo tem como competência garantir a paz. ${ }^{25}$ A federação tem como um dos órgãos do poder judicial o Supremo Tribunal Federativo com competência na resolução de conflitos internacionais.

Esta proposta é também afastada pelo desenvolvimento dos nacionalismos, uma vez os Estados passarem a estar mais cientes da sua própria língua e literatura, do seu passado histórico e da sua individualidade. Como refere Luiz Jardim:

"A solução natural viria da existência dos Estados-Unidos da Europa, a par da dos Estados-Unidos da América, porque então o supremo tribunal federativo resolveria os conflitos internacionais; e, quando eles adviessem entre os povos, o mar separa e aproxima, nesse caso as pendências seriam resolvidas, pela reunião dos dois tribunais. Esta conclusão parece-nos legítima e nela acreditamos. Fazem-na supor, a igualdade de pesos e medidas, a união postal, as transacções de comércio, as literaturas semelhantes, a universalidade da língua francesa, os cabos submarinos, o transporte rápido do pensamento e da matéria pela electricidade e pelo vapor, e finalmente os princípios jurídicos comuns a todos os povos, que hoje se elevam à altura de um direito especial, superior ao direito das gentes. Mas o organizar desde agora, e sem aquela federação um tribunal sobre as nações, coisa nos parece impossível, e nem dela cuidamos que virá a paz." ${ }^{26}$

5. O objectivo de atingir a paz através da modalidade de resolução pacífica de conflitos foi também referido pelo internacionalista português Vicente Ferrer Neto Paiva que, na sua obra Elementos de Direito das Gentes, defende:

"Seria para desejar, que se organizasse não dizermos já a grande associação da humanidade, mas uma associação europêa, procurando tornar uma realidade o que se tem chamado um bello sonho d'alguns Philosophos, como o Abbade de S. Pierre, Kant, Rousseau, etc - a paz perpétua: o Direito das Gentes teria um tribunal, que administrasse justiça entre as nações da Europa, decidindo pacificamente as questões, que se originassem acerca dos seus 25 Cfr. JARDIM, Luiz. Arbitragem Internacional. 2. ed. Lisboa: Cristóvão Augusto Rodrigues, 1893. pp. 85-86. 26 Idem, pp. 87-88. 
direitos. As nações da Grécia nos tempos antigos, com a juncta dos Amphictyões, as da Allemanha nos modernos, com a Dieta germânica, e em geral todas as federações de nações, subministram typos para a organização da grande sociedade da Europa. Os congressos e conferências, que por vezes se têm reunido, provam que as nações da Europa tendem para esta instituição, e que sentem a sua conveniência política."27

Não obstante a posição assumida por Vicente Ferrer Neto Paiva os portugueses não se evidenciaram na construção de projetos federativos. De entre nomes que referenciaram os trabalhos estrangeiros, podemos referir Almeida Garrett, em Portugal na Balança da Europa, in Obras de Almeida Garrett, volume I, Porto, Lello \& Irmão - Editores, s/d, p. 815, e o Major Máximo Pinto da Fonseca Rangel.

6. A defesa da construção da paz não é feita apenas através de propostas de sistemas federativos, mas também pelo desenvolvimento de institutos de caráter político, como o princípio do equilíbrio, o sistema de congressos e o sistema de conferências que, ao longo do século XIX, são responsáveis pelo desenvolvimento do Direito Internacional, entendido como um instrumento de aproximação dos povos e de construtor da paz. O século XIX, em especial após o Congresso de Viena de 1815, pode ser denominado, em nossa opinião, como o período de construção da paz através do direito. ${ }^{28}$

\section{A ARBITRAGEM INTERNACIONAL NO SÉCULO XIX}

1. Na organização e desenvolvimento da sociedade de Estados têm sido prosseguidas diversas soluções para a construção de um sistema jurisdicional.

$\mathrm{Na}$ tentativa de resolução de um qualquer conflito os Estados recorrem em primeiro lugar às negociações diplomáticas, através das quais os representantes de cada Estado têm a missão de restabelecer a paz e amizade entre eles. Quando as negociações são goradas, outros

27 Cfr. PAIVA, Vicente Ferrer Neto. Philosophia de Direito. 5. ed. Coimbra: Imprensa da Universidade, 1905. pp. 2-3.

28 FREITAS, Pedro Caridade de. História do Direito Internacional Público. Da Antiguidade à II Guerra Mundial. Cascais: Princípia, 2015. pp. 101-112. 
meios de resolução pacífica de conflitos são tentados, como os bons ofícios ${ }^{29}$, a mediação ${ }^{30}$ ou a conciliação. ${ }^{31}$

Não obstante a possibilidade de recurso a estes meios, os Estados perceberam que não eram totalmente efetivos, fruto da ausência de obrigatoriedade no cumprimento das decisões decorrentes dos bons ofícios, da mediação ou da conciliação, pelo que procuraram estabelecer outros instrumentos que permitissem concretizar os projectos de paz universal. ${ }^{32}$

Os Estados encaminham-se assim para a definição de outros instrumentos de jurisdição mais efetivos, como a criação de um tribunal internacional e a arbitragem internacional.

A definição de uma jurisdição internacional no século XIX através da criação de um tribunal internacional que vincule todos os Estados torna-se difícil de concretizar, não apenas porque os estados não aceitam vincular-se a entidades supranacionais que pudessem pôr em causa a sua soberania ${ }^{33}$, como é difícil criar um tribunal internacional sem a existência de uma lei de processo que regule as partes no modo de provar o seu direito.

2. Na atualidade, o termo jurisdição internacional, como refere Maria José Rangel de Mesquita apresenta dois sentidos: o material, enquanto autoridade ou competência para declarar o direito para a resolução de um diferendo, e o orgânico, enquanto tribunal internacional. $^{34}$

29 Os bons ofícios consistem na intervenção, por vontade própria, de um terceiro Estado que, por razões de amizade, de vizinhança ou de estratégia, tenta conciliar as posições dos Estados beligerantes. A proposta feita pelo Estado que exerce os bons ofícios não é obrigatória para os Estados beligerantes. Vide FREITAS, Pedro Caridade de. História do Direito Internacional Público. Da Antiguidade à II Guerra Mundial. Cascais: Princípia, 2015. pp. 156-157.

30 A mediação ocorre quando um terceiro Estado, a solicitação dos Estados beligerantes ou por iniciativa de uma terceira potência mas com aceitação dos Estados, presta o seu auxílio para a resolução do conflito. A proposta de resolução feita pelo mediador não é vinculativa para os Estados beligerantes. Idem, pp. 157-158.

31 A conciliação apresenta finalidades semelhantes à mediação e "constitui o processo de resolução de um conflito através do recurso a uma comissão de pessoas escolhidas pelos Estados, cuja tarefa é esclarecer os fatos e ouvir as partes com o objectivo de promover um acordo entre elas. Esse acordo é materializado num relatório preparado pelos conciliadores." A proposta feita pelos conciliadores não é vinculativa para os Estados beligerantes. Idem, p. 158.

32 Martim de Albuquerque entende que a paz universal "pode ser concebida como limitada temporalmente, isto é como uma paz transitória, episódica, momentânea", a paz perpétua "é prefigurável, num aspecto geográfico, como restrita, quer dizer, como uma paz particular, parcial, regionalista." Cfr. ALBUQUERQUE, Martim de. A Paz Universal no Pensamento Político Português. In: ALBUQUERQUE, Martim de. Estudos de Cultura Portuguesa. v. I. Temas Portugueses. Lisboa: Imprensa Nacional - Casa da Moeda, 1984. p. 359.

33 Sobre a soberania no Direito Internacional moderno vide FREITAS, Pedro Caridade de. Portugal e a Comunidade Internacional na Segunda Metade do Século XIX. Lisboa: Quid Juris, 2012. pp. 191-203.

34 Cfr. MESQUITA, Maria José Rangel. Justiça Internacional. Lições. Parte I. Introdução. Lisboa: AAFDL, 2010. p. 91 . 
Como refere ainda Maria José Rangel de Mesquita o conceito de tribunal internacional implica também a existência de um conjunto de requisitos essenciais "a existência de uma decisão, obrigatória para as partes, através da aplicação de regras de processo contraditório que garantam a igualdade das partes e o direito de defesa. ${ }^{, 35}$

Para a existência de um Tribunal Internacional, e depois das experiências do início do século XX, em especial da Sociedade das Nações, tem sido defendida a necessidade de verificação dos seguintes requisitos: (i) permanência; (ii) obrigatoriedade da decisão a proferir; (iii) independência, que se concretiza pela irrelevância da vontade das partes na composição do tribunal e na designação dos seus membros, bem como na sua organização e funcionamento; (iv) aplicação de normas e princípios de direito internacional; (v) natureza jurídica internacional da fonte criadora do tribunal.

O tribunal internacional pode ser criado por um tratado internacional celebrado entre Estados soberanos ou através de um ato derivado aprovado pelo órgão competente de uma organização internacional. A fonte constitutiva de um tribunal internacional determina os aspectos essenciais de jurisdição, competência, constituição, organização e funcionamento. ${ }^{36}$

3. A arbitragem surge como uma forma da sociedade internacional ultrapassar a dificuldade na criação de um Tribunal Internacional e ao mesmo tempo de permitir a jurisdicionalização do sistema internacional.

O século XIX desenvolve o sistema de arbitragem como meio de resolução pacífica de conflitos. Ao longo da centúria são muitos os países que recorrem a este instituto como forma de evitar conflitos armados.

Dentre os assuntos submetidos a arbitragem, podemos realçar os pedidos de indenização referentes a prejuízos causados pela guerra, nomeadamente violação de território neutro, como o caso do Alabama ${ }^{37}$; os pedidos de indenização em benefício de determinadas pessoas pelos ultrajes que elas sofrem e que a nação da sua bandeira considera um ataque ou menosprezo da sua dignidade; as contestações sobre a posse de territórios ou de delimitação

35 MESQUITA, Maria José Rangel. Justiça Internacional. Lições. Parte I. Introdução. Lisboa: AAFDL, 2010. pp. 91-92.

36 Idem, pp. 92-93.

37 Cfr. LOPES, José Alberto Azeredo. Textos Históricos do Direito e das Relações Internacionais. Porto: Universidade Católica Portuguesa, 1999. pp. 123-125; BRY, Georges. Précis Élémentaire de Droit International Public mis au Courant des Progrès de la Science et du Droit Positif Contemporain . 6. ed. Paris: Librairie de la Société du Recueil Sirey, 1910. pp. 493-495. 
de fronteiras; as contestações sobre a validade de certas presas e todas as demais situações em que é violado um dever internacional. ${ }^{38}$

Assim, entre 1798 e 1899 são resolvidos pelo recurso à arbitragem internacional 156 conflitos, de entre questões como as do Alabama, as focas do mar de Behring e a questão das fronteiras dos Andes. ${ }^{39}$

Até ao fim do século XIX, Portugal recorre também à jurisdição arbitral e até ao final do século envolve-se em 9 arbitragens, a que podemos juntar mais 2, no início do século $\mathrm{XX}^{40}$

4. Do conceito amplo de arbitragem subsumem-se duas modalidades: a arbitragem voluntária e a arbitragem obrigatória. ${ }^{41}$

A arbitragem voluntária ocorre quando dois ou mais Estados entram em conflito e decidem solucioná-lo através da submissão da situação ao julgamento de um terceiro Estado. O ato através do qual os Estados convencionam sujeitar a questão à análise de um terceiro é denominado por compromisso arbitral.

A arbitragem obrigatória surge quando dois ou mais Estados convencionam a submissão à arbitragem de todos ou de alguns conflitos que possam surgir entre eles. Regra geral designa-se este tipo de tratados como de arbitragem, uma vez o fim único ser a assunção do compromisso arbitral.

Esclareça-se que, apesar da designação de arbitragem obrigatória, a arbitragem é previamente voluntária, uma vez assentar na vontade dos Estados em convencionar um tratado de arbitragem, daí que se possa dizer que a sentença se fundamenta não apenas na vontade das partes, mas também na existência de uma convenção internacional anterior.

38 Cfr. FREITAS, Pedro Caridade de. Portugal e a Comunidade Internacional na Segunda Metade do Século $X I X$. Lisboa: Quid Juris, 2012. pp. 577-637.935

39 Cfr. CALDAS, Francisco de Castro. Portugal e a Arbitragem Internacional. Lisboa: [s. n.], 1935. pp. 21-25. Sobre a arbitragem internacional vide também ROMANOS, Angel. Elementos de Derecho Internacional Público. Zaragoza: Tip. de Mariano Salas, 1904. pp. 175-202.

40 As arbitragens portuguesas são: a questão General Amstrong, a questão Croft, a questão Yuille, Shortrige \& C.", a questão Ilha de Bolama, a questão da Baía de Lourenço Marques; a questão da Barca Svanen; a questão Lavarello, a questão de Manica, a questão de Barotze e a questão de Timor.

41 Bluntschli defende a existência de dois tipos de arbitragem, a arbitratio, quando as partes estão de acordo quanto à questão de direito, mas não quanto aos efeitos; a arbitrium, quando as partes não estão de acordo quanto ao próprio direito. Cfr. BLUNTSCHLI, Johann Caspar. Le Droit International Codifié. Paris: Librairie de Guillaumin et C. ${ }^{\mathrm{a}}, 1870$. p. 259. 
5. O desenvolvimento e a implementação da arbitragem ao longo do século XIX sofre algumas vicissitudes, fruto da ausência de uma lei internacional uniforme, de um tribunal único e de um processo específico que seja seguido pelas partes em causa.

Apesar de não haver um Direito Internacional convertido em lei, nem uma lei de processo, os árbitros, para a resolução das causas, e de modo a organizar o tribunal arbitral e solucionar as questões suscitadas, podem recorrer às sentenças, aos procedimentos utilizados por outros tribunais, às regras comuns de processo civil e aos usos e costume dos povos. ${ }^{42}$

Para a realização de arbitragens voluntárias é necessário atender alguns elementos, como a escolha do árbitro, o compromisso arbitral, a definição da língua do processo, o processo arbitral, os meios de prova e a sentença arbitral. ${ }^{43}$

5.1. A escolha dos árbitros influi no desempenho do tribunal, no Direito aplicável e no grau de imparcialidade do tribunal. A quem deve ser entregue um tribunal arbitral é uma questão que divide os Estados e os internacionalistas oitocentistas. Os árbitros devem ter como objectivo a prossecução da justiça e a procura da verdade, e ser independentes inclusive da parte que os escolhe. ${ }^{44}$

Relativamente a quem deve ser árbitro, os internacionalistas e os Estados dividem-se em argumentos. Uns dizem que a arbitragem deve ser entregue a Chefes de Estado, Soberanos ou Presidentes de República ${ }^{45}$, outros a autoridades civis ou eclesiásticas, a corporações científicas e de direito, a cidadãos de um terceiro Estado, a particulares de uma das nações ou a delegados de ambas. ${ }^{46}$

42 BLUNTSCHLI, Johann Caspar. Le Droit International Codifié. Paris: Librairie de Guillaumin et C. ${ }^{\text {a }} 1870$. p. 79.

43 Cfr. FREITAS, Pedro Caridade de. História do Direito Internacional Público. Da Antiguidade à II Guerra Mundial. Cascais: Princípia, 2015. pp. 162-169.

44 Cfr. NYS, Ernest. Le Droit International. Les Principes, les Théories, les Faits. v. 1. Nova edição. Paris: Marcel Rivière et C. ${ }^{\text {a }}$ [s. d.]. p. 600.

45 Cfr. A opinião de G. Rolin-Jaequemyns sobre a preferência por juízes que não fossem Chefes de Estado, porque podia prejudicar a decisão, uma vez o escolhido ser amigo das partes em litígio em ROLINJAEQUEMYNS, Gustave. Chronique des Arbitrages Internationaux. RDI, Bruxelas, v. 23, 1891. pp. 201-203.

46 A título meramente exemplificativo refiram-se os árbitros das diversas arbitragens portuguesas: questão General Amstrong, o Presidente da República francesa, Luís Napoleão; questão Ilha de Bolama, o Presidente dos Estados Unidos da América, Ulisses Grant; questão da Baía de Lourenço Marques, o Presidente da República francesa, Mac Mahon; questão da Barca Svanen, o Director da Companhia de Seguros "Gauthiod", Harald Fleetwood; questão Lavarello, o jurisconsulto holandês Heemskerk; questão de Manica, o jurisconsulto italiano Paul Honoré Vigliani; questão de Barotze, o Rei de Itália, Vitor Manuel; questão de Timor, Lardy, membro do Tribunal Permanente de Arbitragem; na questão Croft e na questão Yuille, Shortrige \& C. ${ }^{a}$ o Senado de Hamburgo. 
Portugal é inovador na escolha que faz para dirimir os conflitos Croft e Yuille, Shortrige \& C..${ }^{47}$ Nestas arbitragens sujeita-se o processo ao julgamento do Senado de Hamburgo. Estas duas arbitragens têm suscitado o interesse da jus-historiografia, uma vez reunirem a vantagem do processo ser julgado por um Soberano e por uma comissão mista, numa altura em que se ponderava qual o melhor sistema a seguir.

A diversidade de escolha dos árbitros ao longo do século XIX permite-nos concluir que as arbitragens referentes a questões territoriais têm, em regra, como árbitros Chefes de Estado, dado que estas arbitragens analisam situações em que a soberania territorial de um Estado pode ser colocada em causa, enquanto as arbitragens sobre questões relativas a responsabilidade civil dos Estados ou outras questões de Direito Internacional Privado têm como árbitros, em regra, juristas ou técnicos das áreas em causa.

5.2. Após a escolha dos juízes é celebrado um compromisso, no qual, se precisa a questão a debater, a língua a utilizar no processo, os aspectos de fato e de direito e as atribuições do juiz, bem como os seus limites no momento da decisão. ${ }^{48} \mathrm{O}$ convênio deve ainda definir o direito estabelecido para aplicação dos árbitros e os meios de prova suscetíveis de ser utilizados.

A definição da língua em que o processo arbitral vai decorrer é essencial, e a escolha tem de ser feita no compromisso arbitral. A língua utilizada nas várias arbitragens portuguesas não foi sempre a mesma. Nas questões Croft e Yuille, Shortrige \& C. as compromissos foram redigidos em português e inglês e as sentenças em alemão; na questão de Bolama o compromisso foi redigido em português e inglês e a sentença em inglês; na questão da baía de Lourenço Marques o compromisso foi redigido em português e inglês e a sentença em francês; na questão Barotze o compromisso foi redigido em francês e a sentença em italiano; na questão do General Armstrong, do caminho-de-ferro de Lourenço Marques, Lavarello, Manica e Timor prevaleceu o francês. O inglês prevaleceu na questão da barca Svanen.

5.3. Os compromissos arbitrais podem assumir várias formas. Nuns casos, fazem parte das cláusulas de um acordo celebrado entre duas ou mais entidades, noutros o compromisso

47 Para um estudo sobre estas arbitragens que se referem a situações de denegação de justiça, vide FREITAS, Pedro Caridade de. Portugal e a Comunidade Internacional na Segunda Metade do Século XIX. Lisboa: Quid Juris, 2012. pp. 590-607.

48 Cfr.VATTEL, Emmer de. Le Droit des Gens ou Principes de la Loi Naturelle. Paris: J.P. Aillaud, 1835. 2 v. pp. 53-55. 
pode ser tomado através da troca de notas diplomáticas entre os representantes dos países em litígio.

As cláusulas compromissórias não têm, necessariamente, de ser acordadas na decorrência de um litígio, podem ser previamente definidas em tratados internacionais, para serem utilizadas em caso de litígio.

Para permitir o desenvolvimento regular das arbitragens são exaradas cláusulas que facilitam a resolução de potenciais dificuldades. De entre as várias cláusulas consignadas, realçamos: (i) a cláusula de amigável composição ${ }^{49}$; (ii) o julgamento de equidade $^{50}$; e (iii) a arbitragem sob reserva.

O recurso às cláusulas de amigável composição, bem como ao julgamento por equidade, são indiciadoras do entendimento de um Direito Internacional lacunar. O recurso à equidade é um meio eficaz e lógico de suprir as lacunas do Direito Internacional e de, paralelamente, proceder a um julgamento à luz dos princípios de justiça, afastando-se das regras positivas de Direito Internacional. A equidade ocupa, através da arbitragem, um espaço como fonte de direito internacional subsidiário.

Os compromissos arbitrais firmados deixam, via de regra, aos árbitros a capacidade para determinarem as regras processuais. O processo começa pela instrução, que constitui o momento processual mais importante. É uma fase escrita, onde é aceite um número variado de peças processuais, denominadas memórias justificativas. Às partes é concedido prazo para responderem aos argumentos aduzidos pela parte contrária. ${ }^{51}$

49 A cláusula de amigável composição é estabelecida pela primeira vez na questão de Bolama, entre Portugal e Grã-Bretanha. No artigo IX, alínea 2. ${ }^{\mathrm{a}}$, pode ler-se: "No caso de não poder o árbitro decidir-se inteiramente a favor de qualquer das respectivas reclamações será rogado para que haja de dar uma decisão que, no seu entender, se preste a uma solução equitativa desta questão." Uma cláusula com este teor é também integrada no compromisso sobre a baía de Lourenço Marques. Estes tipos de cláusulas, estabelecidas pela primeira vez pela intervenção de Portugal, passam a integrar os compromissos arbitrais de outros países, ocupando um lugar próprio no Direito Internacional arbitral.

50 No compromisso sobre a barca Svanen estabelece-se o julgamento ex aequo et bono, talvez dada a complexidade das normas positivas para a avaliação da indemnização pelo abalroamento do barco.

51 A arbitragem sobre a questão do General Amstrong constitui uma excepção a estas regras, uma vez que apenas é entregue a correspondência diplomática trocada entre Portugal e os Estados Unidos da América. A arbitragem mais complexa é a do caminho-de-ferro de Lourenço Marques que, entre memórias, réplicas, documentos, relatórios de peritos e pareceres de jurisconsultos, somaram-se mais de cinquenta peças processuais.

Nas questões Croft e Yuille, Shortrige \& C. ${ }^{a}$ permite-se ao árbitro pronunciar-se ex parte na falta de apresentação de memórias pelas partes. Esta cláusula constitui uma das primeiras afirmações de que o resultado da arbitragem não deve estar dependente da vontade das partes. A inclusão da cláusula nestas questões também se justifica pelo facto de a Grã-Bretanha temer que Portugal se oponha ao processo arbitral uma vez ter dúvidas quanto ao recurso à arbitragem para solucionar este tipo de questões, por estarem relacionadas com a aplicação do direito nacional. 
Em regra, a prova é feita através da apresentação de documentos e pelo recurso, quando possível, a exames periciais. Podem também ser admitidos debates, conforme o previsto nos artigos XXXIX e seguintes da Convenção de Haia de $1899 .{ }^{52}$

A sentença corresponde ao culminar do processo arbitral.

5.4. O tribunal tem de criar todas as condições para chegar a uma transação entre as partes, que deve ser alcançada de forma livre, voluntária, pelo que as arbitragens assumem um carácter essencialmente judiciário.

As decisões dos árbitros são tomadas por maioria e são obrigatórias para as partes. Da arbitragem pode resultar para as partes um acordo, corporizado num tratado, a recusa a uma das partes de um direito que invoca ou a renúncia, por uma das partes em contenda, de um determinado direito. ${ }^{53}$

As sentenças devem respeitar sempre as regras gerais, nomeadamente ser fundamentadas, assinadas e notificadas às partes nos prazos processuais estabelecidos. As custas devem ser fixadas pelos árbitros e suportadas em partes iguais. ${ }^{54}$

A regra geral da arbitragem é a de que as sentenças devem ser aceitas pelas partes e devidamente cumpridas.

A sentença proferida constitui caso julgado em relação ao objeto e às partes em litígio.

A doutrina divide-se em relação à execução da sentença arbitral: uns confiam a execução da sentença à boa-fé e honra das partes, outros entendem que a intervenção diplomática colectiva é eficaz para o cumprimento da sentença e, por fim, alguns juristas defendem o recurso a algumas medidas que pressionem a execução. ${ }^{55}$

Para além destas posições, não podemos deixar de considerar que a arbitragem internacional é fundada num compromisso arbitral que assume a natureza jurídica de tratado internacional. Os Estados encontram-se, assim, vinculados ao cumprimento da sentença arbitral que é proferida na decorrência de um processo iniciado com base num tratado internacional que os Estados negociaram, assinaram e ratificaram. O não cumprimento da

52 Vide o texto em HOMEM, António Pedro Barbas; FREITAS, Pedro Caridade de. Textos de Apoio de História das Relações Internacionais. 2. reimpr. Lisboa: AAFDL, 2018. p. 230 e seguintes.

53 Cfr. BLUNTSCHLI, Johann Caspar. Le Droit International Codifié. Paris: Librairie de Guillaumin et C., 1870. p. 261.

54 FREITAS, Pedro Caridade de. Portugal e a Comunidade Internacional na Segunda Metade do Século XIX. Lisboa: Quid Juris, 2012. p. 556.

55 Cfr. NYS, Ernest. Le Droit International. Les Principes, les Théories, les Faits. v. 1. Nova edição. Paris: Marcel Rivière et C. ${ }^{\text {a }}$ [s. d.]. p. 575. 
sentença arbitral constitui, em nossa opinião, a violação de um tratado internacional e consequentemente a violação do princípio pacta sunt servanda.

5.5. A possibilidade de haver recurso das decisões arbitrais foi discutida pelos Estados e pela doutrina internacionalista, em especial no decurso da Convenção de Haia de 1899.

A título meramente exemplificativo refira-se que o internacionalista Martens defende que a revisão da sentença arbitral é contrária à natureza jurídica da arbitragem. ${ }^{56}$ Para Martens, a arbitragem tem como objectivo pôr fim a um conflito e não a perpetuá-lo através de recursos de sentenças. Acresce a este argumento um outro de carácter formal, e que é o da inexistência de uma instância de recurso arbitral, uma vez se tornar inviável a constituição de um novo tribunal arbitral para apreciar o processo em sede de recurso. A arbitragem pretende pôr fim a conflitos entre Estados e não a pendurá-los no tempo.

Não obstante estes considerandos, foi pensada a possibilidade de se realizar um recurso. Quanto à forma de organizar o recurso, uns jurisconsultos propõem que o Estado lesado recorra à via diplomática, outros sugerem que a revisão seja feita pelos árbitros que proferem a sentença, e outros ainda propõem organizar um processo de revisão das sentenças arbitrais.

A decisão do tribunal arbitral pode ser considerada nula, nas seguintes situações: ${ }^{57}$

i) no caso de o tribunal arbitral ultrapassar as competências definidas no compromisso;

ii) no caso de deslealdade ${ }^{58}$ e denegação de justiça por parte dos árbitros;

iii) no caso de recusa em ouvir as partes ou violação de qualquer princípio fundamental do processo; ${ }^{.5}$

56 NYS, Ernest. Le Droit International. Les Principes, les Théories, les Faits. v. 1. Nova edição. Paris: Marcel Rivière et C. ${ }^{\mathrm{a}}$, [s. d.]. p. 615.

57 Cfr. BLUNTSCHLI, Johann Caspar. Le Droit International Codifié. Paris: Librairie de Guillaumin et C., 1870. p. 261. Sir Travers Twiss, na obra Law of nations, defende que "quand les nations se sont accordées pour déférer à un arbitrage une question en litige entre elles, leur bonne foi est engagée à obéir à la décision de l'arbitre, à moins que cette décision n'implique une dérogation manifeste aux termes du compromis, ou qu'elle ne soit absolument contraire aux règles de la justice et, par conséquent, ne puisse servir de base à une convention internationale valable, ou qu'elle ne soit le résultat d'une fraude ou d'une connivence entre l'arbitre et l'une des parties.", cfr. NYS, Ernest. La Revision de la Sentence Arbitrale. Revue de Droit International et Législation Comparée. t. 12., 1910., p. 601. Vide um exemplo de uma sentença considerada nula na obra de Ernest Nys referida a pp. 621-641.

58 Blunstschli dá como exemplo a corrupção dos árbitros por uma das partes. Cfr. BLUNTSCHLI, Johann Caspar. Le Droit International Codifié. Paris: Librairie de Guillaumin et C. a $^{2}$ 1870. p. 261.

59 "Les arbitres, étant revêtus de fonctions quasi-judiciaires, doivent respecter les principes fondamentaux de la procédure. Leur décision ne peut être attaquée pour de simples vices de forme, mais elle sera nulle s'ils ont violé d'une manière directe et évidente les principes généraux de la procédure ; s'ils ont, par exemple, interdit aux parties de formuler leurs demandes ou de réfuter les prétentions de leur adversaire, celles-ci ne seront pas tenues de se soumettre à une décision aussi arbitraire.”, Idem, anotações ao art. 495, p. 261. 
vi) no caso de a decisão ser contrária ao direito internacional; ${ }^{60}$

v) se os árbitros se encontrarem numa situação de incapacidade legal ou moral, nomeadamente se tiverem um interesse directo na decisão;

vi) Se as partes e o árbitro não agirem de boa fé;

vii) se a sentença se fundar em questões não pertinentes ou essenciais;

viii) se os árbitros se pronunciarem sobre questões não demandadas.

Ao invés, a decisão arbitral não pode ser atacada por vício de forma, por não se encontrar conforme com as regras da equidade, por assentar num princípio errôneo ou por prejudicar uma das partes na contenda. ${ }^{61}$

A doutrina divide-se quanto à forma de organizar o recurso. Uns jurisconsultos propõem que o Estado lesado recorra à via diplomática, outros sugerem que a revisão seja feita pelos árbitros que proferem a sentença e outros ainda propõem-se organizar um processo de revisão das sentenças arbitrais.

As Conferências de Haia de 1899 e de 1907, que prevêem a arbitragem necessária, consagram um artigo específico para a nulidade das sentenças e optam por atribuir a competência para a revisão da sentença arbitral ao tribunal que a profere.

\section{A CRIAÇÃO DE UM TRIBUNAL DE ARBITRAGEM INTERNACIONAL}

1. Os Estados reunidos nas conferências de Haia de 1899 e 1907 defendem a criação de um tribunal de arbitragem internacional e de um sistema de arbitragem necessária.

A regulação da arbitragem internacional encontra-se no título IV, art.s XV e seguintes da Convenção de 1899.

O artigo XV da Convenção de 1899 prevê "A arbitragem internacional tem por fim a solução dos litígios entre os estados por juízes escolhidos pelos mesmos, e sobre a base do respeito do direito". ${ }^{62} \mathrm{Na}$ definição de arbitragem internacional constante deste artigo podem ser individualizados três requisitos, sendo que o primeiro constitui também o objetivo: solucionar litígios entre Estados, por meio de juízes escolhidos pelas partes e no respeito pelo direito, ou, em nossa opinião, no cumprimento das regras do ordenamento jurídico internacional, onde se incluem, os princípios gerais de Direito Internacional, o costume

60 Como exemplo pode imaginar-se o caso da sentença determinar a perda de nacionalidade.

61 Cfr. BLUNTSCHLI, Johann Caspar. Le Droit International Codifié. Paris: Librairie de Guillaumin et C.a, 1870. pp. 261-262.

62 Cfr. HOMEM, António Pedro Barbas; FREITAS, Pedro Caridade de. Textos de Apoio de História das Relações Internacionais. 2. reimpr. Lisboa: AAFDL, 2018. p. 224. 
internacional, o direito convencional, assim como a possibilidade de resolução do conflito pelo recurso aos juízos de equidade.

A arbitragem é reconhecida pelas potências signatárias da Convenção como um instrumento adequado para dirimir questões de interpretação e aplicação das convenções internacionais e para resolver de forma equitativa litígios que não tivessem alcançado solução por via diplomática.

As regras previstas na Convenção de Haia assumem um carácter subsidiário, uma vez que se mantém como regra geral o acordo das partes para a definição e aplicação da justiça arbitral. A título exemplificativo atente-se no teor do artigo XXX que referencia as regras do procedimento arbitral, se outras não tiverem sido estipuladas pelas partes.

A Conferência não logrou mais que aconselhar a arbitragem como o meio adequado para evitar ou solucionar conflitos, tendo sido afastada a ideia da arbitragem obrigatória.

Não obstante não se ter dado o passo em direção à arbitragem necessária, os Estados signatários reconhecem a vantagem do recurso à arbitragem para a resolução de conflitos internacionais, assim como procedem à indicação de diversas individualidades de reconhecido mérito para integrarem a lista de árbitros, viabilizando, desta forma, a constituição do tribunal arbitral.

A Convenção prevê, no artigo XX e seguintes, a criação de um Tribunal Permanente de Arbitragem, com sede em Haia, com objectivos de antepor a resolução pacífica de conflitos à declaração de guerra. O tribunal é competente para todos os casos de arbitragem, desde que as partes não tenham acordado a aplicação de uma jurisdição especial. Não se trata da criação física de um Tribunal, mas, como dispõe o artigo XXIII, de uma lista permanente de árbitros indicado por cada Estado que podem ser escolhidos pelas partes para a resolução dos conflitos internacionais.

A organização e funcionamento do Tribunal compete a um Conselho Internacional composto por representantes de todos os Estados acreditados em Haia. Um bureau internacional serve de cartório do Tribunal.

O artigo XXIV prevê a hipótese dos Estados em litígio não chegarem a acordo sobre os árbitros da lista. Neste caso, o Tribunal constituir-se-ia de acordo com as seguintes regras: “cada uma das partes nomeará dois árbitros e estes escolherão em comum um árbitro de desempate. No caso de divisão de votos será a escolha do árbitro de desempate confiada a outra potência designada de comum acordo pelas partes. Se a este respeito se não chegar a 
acordo, cada uma das partes designará uma potência diferente e a escolha do árbitro de desempate será feita por combinação das potências assim designadas."

A composição do Tribunal Permanente de Arbitragem respeita o princípio da igualdade dos Estados soberanos em Direito Internacional.

2. O processo arbitral encontra-se previsto nos artigos XXX a LVII da Convenção. As potências que pretendam recorrer à arbitragem têm de firmar um compromisso onde determinam o objecto do litígio e a amplitude dos poderes dos árbitros. Com a assinatura do compromisso as partes assumem submeter-se de boa-fé à sentença arbitral.

A tramitação processual geral encontrava-se definida nos artigos XXX e seguintes. A tramitação prevista pode sofrer exceções, nos termos do artigo XXXIII, no caso do árbitro escolhido ser um Soberano ou um Chefe de Estado, por ter competência para definir o procedimento arbitral.

O processo arbitral encontrava-se dividido em duas partes: a instrução e os debates. A instrução, como indica o artigo XXXIX, §2, “consiste na comunicação, pelos agentes respectivos, aos membros do tribunal e à parte contrária, de todos os atos impressos ou escritos, e de todos os documentos contendo as alegações invocadas na causa." Os debates, como dispõe o artigo XXXIX, § 3, são constituídos por exposições e alegações orais das partes perante o tribunal.

Finda a instrução e as alegações, o tribunal arbitral tem de proferir sentença. $O$ tribunal, nos termos do artigo XLVIII, está autorizado a "determinar a sua competência interpretando o compromisso, bem como os outros tratados que no assunto [pudessem] ser invocados, e aplicando os princípios de direito internacional."

A sentença deve ser tomada por maioria de votos, reduzida a escrito e assinada pelos árbitros, que têm a possibilidade, caso não concordem com a mesma de lavrar voto de vencido, como disposto no artigo LII.

A sentença decide a questão submetida a arbitragem de forma definitiva e sem apelação. O compromisso pode consagrar, nos termos do artigo LV, a possibilidade de ser pedida a revisão da sentença arbitral no caso exclusivo de ser descoberto um fato novo "de natureza tal que pudesse ter exercido uma influência decisiva na sentença e que por ocasião do encerramento dos debates fosse desconhecido do tribunal e da parte que pede a revisão." O pedido de revisão é endereçado ao tribunal que tenha proferido a sentença. ${ }^{63}$

63 O pedido de existência de um artigo sobre a revisão de sentença é feito pela delegação russa. A solução encontrada pelos Estados não corresponde ao teor da proposta russa, que propõe uma redacção mais ampla, com 
A sentença arbitral só tem eficácia inter partes, ou seja, vincula apenas as partes que tenham assinado o compromisso. O artigo LVI consagra, no §2, excepções a este princípio geral: "quando se tratar da interpretação de uma convenção em que sejam partes outras potências além das partes litigantes, deverão estas notificar às primeiras o compromisso que celebrarem. Cada uma daquelas potências terá o direito de intervir no processo. Se uma ou mais de entre eles usarem dessa faculdade, terá também força obrigatória a seu respeito a interpretação contida na sentença."

3. A Conferência de 1907 reuniu também na cidade de Haia e juntou 44 Estados, num total de 175 delegados.

A conferência aprova treze convenções e em matéria de resolução pacífica de conflitos tenta criar um tribunal de arbitragem e aprovar o princípio da arbitragem obrigatória. Estes dois objetivos não são bem-sucedidos e os Estados em Conferência não chegam a um entendimento, que pelas regras de então tinha de ser por unanimidade.

Não obstante os esforços diplomáticos de Portugal, adepto da adoção da arbitragem necessária, o princípio não é adotado. No entanto, aprova-se uma declaração indicativa que reconhece de forma unânime o princípio da arbitragem obrigatória ou necessária, sem o adotar como mandatório. ${ }^{64}$

A Segunda Conferência de Haia, ao invés da primeira, não logra criar um Tribunal de Justiça Arbitral, em virtude do desacordo dos Estados presentes quanto à forma de designação dos juízes.

Se na Primeira Conferência o princípio seguido é o da igualdade dos Estados soberanos, nesta Segunda Conferência os Estados Unidos, a Alemanha e a Grã-Bretanha propõem um Tribunal Internacional de Justiça composto por 17 juízes, todos jurisconsultos, dos quais, pelo menos, metade são representantes das grandes potências e os restantes nomeados pelos outros Estados. Acresce ainda que a proposta prevê que cada Estado no período de 12 anos nomeie um juiz, sendo que a duração efetiva do mandato é diferente consoante o Estado representado pelo juiz. Os juízes indicados pelas grandes potências são

o seguinte teor: "la sentence arbitrale est nulle en cas de compromis nul, ou d'excès de pouvoir, ou de corruption prouvée d'un des arbitres.", cfr. NYS, Ernest. Le Droit International. Les Principes, les Théories, les Faits. v. 1. Nova edição. Paris: Marcel Rivière et C. a, [s. d.]. p. 614.

64 Vide FREITAS, Pedro Caridade de. Portugal e a Comunidade Internacional na Segunda Metade do Século $X I X$. Lisboa: Quid Juris, 2012. p. 574. 
nomeadas para todo o período do mandato, as restantes para um lapso temporal limitado e dependente de elementos variáveis. ${ }^{65}$

Nesta proposta há uma preponderância das grandes potências e uma imposição do seu direito, face aos restantes Estados. ${ }^{66}$

A proposta não é aceita, por violadora do princípio da igualdade formal dos Estados, como defendido pelo representante do Brasil, Doutor Rui Barbosa. Os Estados votam uma recomendação para que as potências adotem o projeto se se viesse a chegar a acordo sobre a constituição do tribunal e a escolha dos juízes.

A Convenção de Haia de 1907 não introduz grandes diferenças em relação ao texto de 1899, prevendo-se um processo sumário de arbitragem e a possibilidade do compromisso arbitral ser estabelecido pelo Tribunal, no caso de as partes não chegarem a acordo. ${ }^{67}$

\section{REFERÊNCIAS}

ABBAGNANO, Nicola. Historia da Filosofia. v. 8. Lisboa: Presença, 1984.

ALBUQUERQUE, Martim de. A Paz Universal no Pensamento Político Português. In: ALBUQUERQUE, Martim de. Estudos de Cultura Portuguesa. v. I. Temas Portugueses. Lisboa: Imprensa Nacional - Casa da Moeda, 1984.

BLUNTSCHLI, Johann Caspar. Le Droit International Codifié. Paris: Librairie de Guillaumin et C. ${ }^{\mathrm{a}}, 1870$.

BRY, Georges. Précis Élémentaire de Droit International Public mis au Courant des Progrès de la Science et du Droit Positif Contemporain. 6. ed. Paris: Librairie de la Société du Recueil Sirey, 1910.

CALDAS, Francisco de Castro. Portugal e a Arbitragem Internacional. Lisboa: [s. n.], 1935.

FIORE, Pasquale. Le Droit International Codifié et sa Sanction Juridique. Tradução do italiano por Ch. Antoine. Paris: A. Pedone, 1911.

FREITAS, Pedro Caridade de. Portugal e a Comunidade Internacional na Segunda Metade do Século XIX. Lisboa: Quid Juris, 2012.

65 FREITAS, Pedro Caridade de. Portugal e a Comunidade Internacional na Segunda Metade do Século XIX. Lisboa: Quid Juris, 2012. p. 22.

66 Vide a defesa feita pelo representante brasileiro, Rui Barbosa, do princípio da igualdade de representação na Corte Internacional de Justiça em NUNES, Reginaldo. Rui Barbosa. As Duas Conferências De Haia. O Supremo Tribunal Federal e o Instituto dos Advogados. Rio de Janeiro: Fontes, 1985. pp. 36-40.

67 FREITAS, Pedro Caridade de. Portugal e a Comunidade Internacional na Segunda Metade do Século XIX. Lisboa: Quid Juris, 2012. p. 575. 
FREITAS, Pedro Caridade de. História do Direito Internacional Público. Da Antiguidade à II Guerra Mundial. Cascais: Princípia, 2015.

HOMEM, António Pedro Barbas; FREITAS, Pedro Caridade de. Textos de Apoio de História das Relações Internacionais. 2. reimpr. Lisboa: AAFDL, 2018.

JARDIM, Luiz. Arbitragem Internacional. 2. ed. Lisboa: Cristóvão Augusto Rodrigues, 1893.

KANT, Immanuel. A Paz Perpétua e Outros Opúsculos. Lisboa: Edições 70, 2008.

LIMA, Lobo d'Ávila. Da Sociedade das Nações. Lisboa: J. Rodrigues e C. a, 1927.

MALTEZ, José Adelino. Princípios de Ciência Política. Introdução à Teoria Política. 2. ed. Com prefácio de Adriano Moreira. Lisboa: Instituto Superior de Ciências Sociais e Políticas, 1996.

LOPES, José Alberto Azeredo. Textos Históricos do Direito e das Relações Internacionais. Porto: Universidade Católica Portuguesa, 1999.

MESQUITA, Maria José Rangel. Justiça Internacional. Lições. Parte I. Introdução. Lisboa: AAFDL, 2010.

MONCADA, Cabral de. Filosofia do Direito e do Estado. v. 1. Coimbra: Coimbra Ed., [s.d.].

NUNES, Reginaldo. Rui Barbosa. As Duas Conferências De Haia. O Supremo Tribunal

Federal e o Instituto dos Advogados. Rio de Janeiro: Fontes, 1985.

NUSSBAUM, Arthur. História del Derecho Internacional. v. 1 e 2. Madrid: Editorial Revista de Derecho Privado, [s. d.].

NYS, Ernest. Le Droit International. Les Principes, les Théories, les Faits. v. 1. Nova edição. Paris: Marcel Rivière et C. ${ }^{\mathrm{a}}$, [s. d.].

NYS, Ernest. La Revision de la Sentence Arbitrale. Revue de Droit International et Législation Comparée. t. 12., 1910.

PAIVA, Vicente Ferrer Neto. Philosophia de Direito. 5. ed. Coimbra: Imprensa da Universidade, 1905.

PEREIRA, Maria de Assunção do Vale. A Intervenção Humanitária no Direito Internacional Contemporâneo. Coimbra: Coimbra Ed., 2009.

ROLIN-JAEQUEMYNS, Gustave. Chronique des Arbitrages Internationaux. RDI, Bruxelas, v. 23, 1891.

ROMANOS, Angel. Elementos de Derecho Internacional Público. Zaragoza: Tip. de Mariano Salas, 1904. 
SCOTT, James Brown. El Origen Español del Derecho Internacional Moderno. Prólogo de Camilo Barcia Trelles. Valladolid: Universidad de Valladolid, 1928.

TRUYOL Y SERRA, António. Noções Fundamentais de Direito Internacional Público. 2. ed. Refundida e aumentada. Tradução de R. Ehrhardt Soares. Coimbra: Arménio Amado, 1962.

TRUYOL Y SERRA, António. História da Filosofia do Direito e do Estado. 2. Do Renascimento a Kant. Tradução portuguesa por RUAS, Henrique Barrilaro da 3. ${ }^{a}$ edição espanhola. Lisboa: Instituto Novas Profissões, 1990. (Coleção de estudo geral)

VATTEL, Emmer de. Le Droit des Gens ou Principes de la Loi Naturelle. Paris: J.P. Aillaud, 1835. $2 \mathrm{v}$.

\section{DADOS DA PUBLICAÇÃO}

Categoria: artigo de autor convidado.

Recebido em: 05/07/2020.

Aceito em: 20/07/2020. 
